\title{
A Comparative Assessment of the Effect of Climatic Variations on the Crops of the Cameroon Development Corporation (CDC): Adaptation Options
}

\author{
Jude Ndzifon Kimengsi ${ }^{1}$ \& Nkwainguh Gladston Muluh ${ }^{2}$ \\ ${ }^{1}$ Department of Geography and Environmental Studies, Catholic University of Cameroon Bamenda, Cameroon \\ ${ }^{2}$ Department of Economics and Management University of Buea, Buea, Cameroon \\ Correspondence: Jude Ndzifon Kimengsi, Department of Geography and Environmental Studies, Catholic \\ University of Cameroon, P. O. Box 782, Bamenda, Cameroon. E-mail: ukjubypro2@yahoo.com
}

Received: December 5, 2012 Accepted: January 10, 2013 Online Published: January 30, 2013

doi:10.5539/enrr.v3n1p144 URL: http://dx.doi.org/10.5539/enrr.v3n1p144

\begin{abstract}
It is a truism that the Cameroon Development Corporation (CDC), through the establishment of her plantations, is a major development partner in Cameroon; it is the second largest employer after the government. This corporation principally cultivates three tradables, they include, rubber, oil palm and banana. The large scale cultivation of these tradables contributes significantly to Cameroon's agricultural exports. However, it is observed that variations in climate have an effect on the output of these tradables. This study attempts a comparative assessment of the effects of climatic variations on CDC's rubber, oil palm and banana; it identifies the extent to which the observed 16 year fluctuations in rainfall and temperature have affected the output of the three tradables. Climatic data, which constituted essentially of rainfall and temperature, was obtained for a 16 year period (1995-2010) in each of the plantation sites while the output for these three tradables were also obtained from the CDC Group Rubber, Oil palm and Banana Departments. Trend analyses were done to establish variations in temperature and rainfall while the error correction model was employed to determine the impact of such variations on the output of the three tradables. In order to ensure the robustness of the results, the Phillips Perron unit root test statistics was employed to test for stationarity and the results for each of the variables used in the error correction model equations for the different crops confirm that all the variables were stationary after the first differencing. In addition, the Durbin Watson test for the presence of serial correlation and the semi-robust standard error was used to take care of potential problems of heteroskedasticity. It was established that there is an observed variation in climate and such variations have a profound effect on the three tradables, although the magnitudes vary. The production trend for all the tradables show an average decline in yields from 1.6 tons to 1 ton per hectare for rubber, 7.5 to 5.1 tons per hectare for oil palm and 41.9 to 23 tons per hectare for banana between 1995 and 2010. Generally, the findings show that increasing temperature and declining rainfall have significant and varied effects on the outputs of these perennial crops of the CDC. In the circumstances therefore, the study recommends crop-specific adaptation measures which could be adopted by the CDC to reduce the effects of climatic variations on these tradables.
\end{abstract}

Keywords: temperature, rainfall, variations, CDC, adaptation and Cameroon

\section{Introduction}

Although the assessment and projection of climatic scenarios for Cameroon is constrained by limited climatic data, there is overwhelming evidence that the day to day changes in the pattern of weather indicates that climate change is a reality. Hence, it is no longer a debated fact that both short and long term alterations in climate are experienced in Cameroon and this affects agriculture. This situation is a cause for concern considering the fact that agriculture is the bread basket for the Cameroonian economy. Located in Western Central Africa, on the Coast of the Gulf of Guinea, between latitudes $3-13^{\circ} \mathrm{N}$, Cameroon is one of the countries in Africa whose geographical position provides many opportunities for diversed agricultural production. The Cameroonian economy is largely agrarian. Agriculture contributes about 35\% of Cameroon's Gross Domestic product and accounts for close to $70 \%$ of the national labour force (Molua \& Lambi, 2006). This dependence reflects the heavy emphasis on the agricultural sector and the limited strength of the industrial sector. Plantation agriculture 
in Cameroon is carried out by major corporations such as Société Camerounaise des Palmiers (SOCAPALM), Plantation du Haut Penja (PHP), Pamol Plantations Ltd and the CDC. These agro-industrial establishments are the fundamental cells of modern economic life because they shape the physical and social part of their region of operation. It has been generally agreed that the establishment of these plantations remain a major driving force for socio-economic and infrastructural development (Kimengsi, 2008) and regional development (Fossung, 2001). The dynamism of modern agricultural organisations or corporations have transformed nature and our society. In recent times, corporate agriculture faces a number of challenges with the variations in climate being a major one.

The CDC is preoccupied with plantation agriculture. It is synonymous to corporate agriculture which is defined in accordance with the ILO Plantations Convention No. 110 of 1958 as "any agricultural undertaking regularly employing hired workers which is situated in the tropical or sub tropical regions and which is mainly concerned with the cultivation or production for commercial purposes of coffee, tea, sugar cane, rubber, bananas, cocoa, coconut, groundnut, cotton, tobacco, fibres, citrus, palm oil or pineapple". The CDC was incorporated in 1947 with the mission to acquire, develop and operate extensive plantations of tropical crops. The CDC is principally located in the South West and Littoral Regions of Cameroon and it cultivates rubber, oil palm and banana on a surface area of 41,874 hectares. The current annual production for these tradables is 18,744 tons of processed rubber, 12,355 tons of palm oil, and 100,952 tons of premium quality banana (CDC Budget Booklet 2011). The average annual turnover since 2008 has been above 50 billion CFA francs. This corporation employs about 22,431 workers and it is the second largest employer in Cameroon after the government. The CDC practises the rain-fed system of agriculture in the growing of her rubber and oil palm and irrigated farming in the growing of bananas. These systems of agriculture are vulnerable to variations in climatic conditions.

\subsection{The Problem}

The three tradables which are cultivated by the CDC, that is, rubber, oil palm and banana are affected by variations in climate as observed for the 16 year period (1995-2010). The variation in climate which essentially constitutes temperature and rainfall affect the three tradables in varying magnitudes. This situation which hinges on the variations in the microclimatic requirements of the three tradables has led to a decline in the yields of rubber, oil palm and banana from 1.6 tons per ha to 1.0 ton, 7.5 to 5.1 tons and 41.9 to 23 tons per ha respectively between 1990 and 2010. Given that the CDC as a corporation has significantly expanded her relative capital, re-organised the management of her plantations and intensified her supervision and it is still experiencing a decline in crop output over time when compared to when it was established, it is important to find out the extent to which climatic variations have contributed to such fluctuations in output which essentially assumes a decreasing trend. In line with Cameroon's strive towards emergence come 2035, and considering the fact that this emergence hinges on the development of her agricultural base, particularly plantation agriculture, it becomes necessary to make a comparative assessment of the effect of climatic variations on the three tradables of the CDC and to recommend crop-specific adaptation measures which could be adopted by the CDC to reduce the effects of climatic variations on these tradables.

\subsection{Literature Review}

Extensive literature exists on the effect of short and long term climate change on agriculture. It has been established that the impacts of climatic variations and change are likely to be considerable in tropical regions. On the whole, it is projected that crop yields may fall by 10 to $20 \%$ by 2050 because of warming and drying; but there are places in Sub-Saharan Africa where yield losses may be much more severe (Jones \& Thornton, 2003). Developing countries are generally considered to be more vulnerable to the effects of climate change than the developed countries, this is because they have a low capacity to adapt to climate related stress (Thomas \& Twyman, 2005).

Lordemann and Salas (2009) are of the opinion that it is not surprising that agriculture which is an important economic activity is vulnerable to climate variability and change. For the developing regions of the world, many countries in Africa are seen as being the most vulnerable to climatic variations and change (Slingo et al., 2005). According to Okunmadewa (2003), vulnerability is the likelihood of a shock causing a significant welfare loss (cited in Oyekale et al., 2009). The degree of vulnerability depends on exposure to risks (uncertain events that can lead to welfare losses) and on risk management actions taken to respond to risks, which may be ex-ante (before) or ex-post (after). High levels of vulnerability and low adaptive capacity in the developing world have been linked to poverty and the heavy dependence on the natural resource base, limited ability to adapt financially and institutionally, low per capita GDP, among others (Thomas \& Twyman, 2005). Considerable efforts are made by development agencies and governments to come to overcome climate-related challenges, including the 
development of appropriate adaptation strategies such as the introduction of new crop varieties and the development of epidemiological surveys to handle the complex problems of climate change (Thornton et al., 2006). This is particularly so, for governments whose economies rely largely on the agricultural sector.

The call for adaptation continues to feature in the literature for climate variations and change. This entails the need to increase the adaptive capacity of agricultural systems in the face of a capricious climatic scenario. According to the Inter-governmental Panel on Climate Change (IPCC, 2001) adaptive capacity is the ability of a system to adjust to climate change (including climate variability and extremes), to moderate potential damages, to take advantage of opportunities, or to cope with consequences (cited in Oyekale et al., 2009). The goal of adaptation measure should be to increase the capacity of a system to survive external shocks or changes.

Important adaptation options in the agricultural sector include crop diversification, mixed cropping, livestock farming system, using different crop varieties, changing planting and harvesting dates, mixing less productive, drought resistant varieties and high yield water sensitive crops (Jagtap, 1995 cited in Oyekale et al., 2009). Agriculture adaptation involves 2 types of modifications in production systems. The first is increased diversification that involves engaging in production activities that are drought tolerant and or resistant to temperature stresses as well as activities that make efficient use and take full advantage of prevailing water and temperature conditions, among other factors. Crop diversification can serve as insurance against rainfall variability as different crops are affected differently by climate events (Oyekale et al., 2009).

\section{Method}

\subsection{Study Site}

The CDC's operational plantations are mainly found in the South West and Littoral regions of Cameroon (Figure 1). It maintains an extensive network of meteorological stations throughout their plantations in the region. A set of weather stations were selected on the basis of geographical distribution. The monthly average temperature in the rubber plantation is $27.02{ }^{\circ} \mathrm{C}$ and rainfall is $245.18 \mathrm{~mm}$, with the number of rainy days above the upper limit of 150 days in a year. In the palm plantations, monthly average temperature is $26.70{ }^{\circ} \mathrm{C}$ and the mean monthly rainfall is $550 \mathrm{~mm}$. For the banana plantations the average monthly temperature is $28.05^{\circ} \mathrm{C}$, and rainfall was at $238.78 \mathrm{~mm}$.

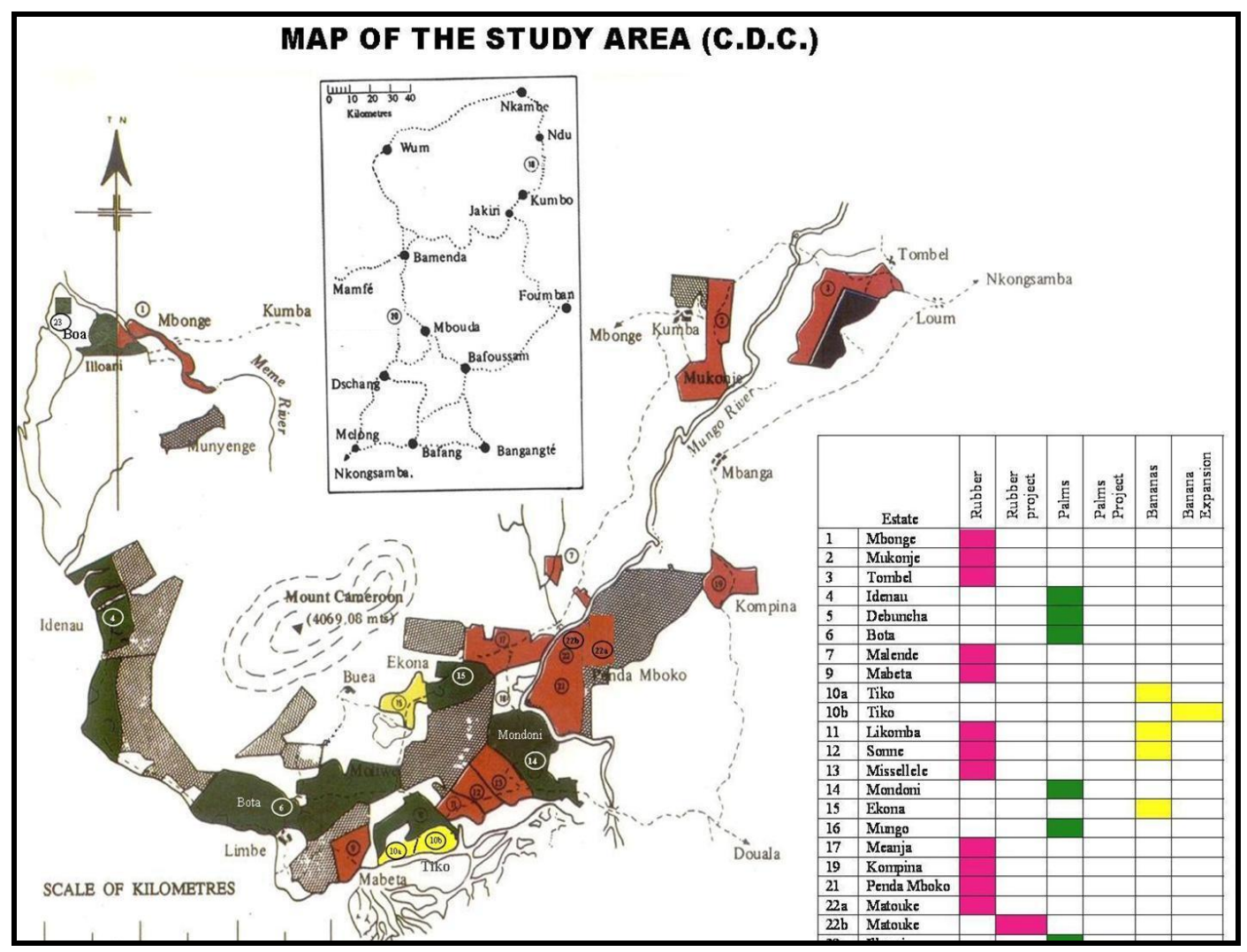

Figure 1. Location of CDC Plantations

Source: CDC Annual Report, 2011. 
The CDC's oil palm, rubber and banana plantations are spread out in the mono-modal humid forest agro-ecological zone in Cameroon. The location sites of the three crops are influenced by the local climatic conditions and the soil type. The rubber crop does well in areas with temperature of $28^{\circ} \mathrm{C}$ plus or minus $2{ }^{\circ} \mathrm{C}$ and with an annual rainfall of about $3000 \mathrm{~mm}$ evenly spread in the year (CDC Group Rubber Monthly Activity Reports, 1995-2010). The oil palm requires a maximum of $31{ }^{\circ} \mathrm{C}$ and a minimum of $25{ }^{\circ} \mathrm{C}$ and a minimum rainfall of 2000mm (CDC Group Oil Palm Monthly Activity Reports, 1995-2010) meanwhile the banana fruit requires a mean monthly temperature of $27^{\circ} \mathrm{C}$ and rainfall in the range of 2500 to $3000 \mathrm{~mm}$ annually evenly distributed (CDC Group Banana Monthly Activity Reports, 1995-2010). From the climatic requirements, it is observed that variations in temperature and rainfall for the 16 year period have been very significant and this has affected the output of the three tradables.

\subsection{Research Methods}

Secondary data for this research was obtained from the CDC Meteorological Data Office at Tiko. In addition, data for the three tradables were collected from the Statistics and Management Control and Accounts Offices of the CDC. Also, some data was collected from articles, journals, seminar papers, CDC activity reports and budget booklets, annual reports, the CDC oil palm, rubber and banana field operation manuals. Principally, the secondary method of data collection was used to put together the required data for this study. The study made use of time series data for climate (temperature and rainfall) and the output of the three tradables (rubber, oil palm and banana) for a 16 year period (1995-2010). Trend analyses were done to establish climatic variations specifically for temperature and rainfall. In addition, the error correction model was employed to determine the impact of such variations on the output of rubber, oil palm and banana. The error correction model is adopted to estimate the time series data that is established between 1995 and 2010. A key assumption of this model is that cooler periods will behave like the patterns observed in warmer periods if they were subjected to climatic alterations. It also assumes that crop responses to climate variability are already present in observed data. Such economic trends imposed by climate variability have already been made over time and cannot be changed. The error correction model employed is a product of the Modified Cobb-Douglas Production Function. This was simplified and developed into three main models. Model 1 for the rubber, Model 2 for oil palm with four variables each and model 3 for banana with six variables (including fertilizer and pesticides costs). These models are estimated for the individual crops to test for any difference in the rate at which they are affected by variations in climate. The models are presented thus:

Model 1 for the Rubber crop is stated as follows:

$$
\begin{aligned}
\Delta \text { Out }_{\mathrm{t}} & =\beta_{0}+\beta_{1} \Delta \text { temp }_{\mathrm{t}}+\beta_{2} \Delta \text { rainf }_{\mathrm{t}}+\beta_{3} \Delta \mathrm{lab}_{\mathrm{t}}+\beta_{4} \Delta \mathrm{Cap}_{\mathrm{t}}+\alpha_{1} \text { Out }_{\mathrm{t}-1}+\alpha_{2} \text { temp }_{\mathrm{t}-1}+\alpha_{3} \text { Rainf }_{\mathrm{t}-1}+ \\
\alpha_{4} \mathrm{XLab}_{\mathrm{t}-1}+\alpha_{5} \mathrm{Cap}_{\mathrm{t}-1}+\mathrm{e}_{\mathrm{t} 1} & \ldots
\end{aligned}
$$

Model 2 for the Oil palm crop is stated as follows:-

$$
\begin{aligned}
& \Delta \text { Out }_{\mathrm{t}}=\beta_{0}+\beta_{1} \Delta \text { temp }_{\mathrm{t}}+\beta_{2} \Delta \text { Rainf }_{\mathrm{t}}+\beta_{3} \Delta \mathrm{Lab}_{\mathrm{t}}+\beta_{4} \Delta \text { Cap }_{\mathrm{t}}+\alpha_{1} \text { Out }_{\mathrm{t}-1}+\alpha_{2} \text { Temp }_{\mathrm{t}-1}+\alpha_{3} \text { Rainf }_{\mathrm{t}-1} \\
& \quad+\alpha_{4} \mathrm{Lab}_{3 \mathrm{t}-1}+\alpha_{5} \text { Cap }_{4 \mathrm{t}-1}+\mathrm{e}_{\mathrm{t} 2}
\end{aligned}
$$

Model 3 for the banana crop (Inclusion of fertilizer and pesticides cost).

$$
\begin{aligned}
\Delta \text { Out }_{\mathrm{t}}= & \beta_{0}+\beta_{1} \Delta \text { Temp }_{\mathrm{t}}+\beta_{2} \Delta \text { Rainf }_{\mathrm{t}}+\beta_{3} \Delta \text { Lab }_{\mathrm{t}}+\beta_{4} \Delta \text { Cap }_{\mathrm{t}}+\beta_{5} \Delta \text { Fert }_{\mathrm{t}}+\beta_{6} \Delta \text { Pest }_{\mathrm{t}}+\alpha_{1} \text { Out }_{\mathrm{t}-1}+ \\
& \alpha_{2} \text { Temp }_{\mathrm{t}-1}+\alpha_{3} \text { Rainf }_{\mathrm{t}-1}+\alpha_{4} \text { Lab }_{\mathrm{t}-1}+\alpha_{5} \text { XCap }_{\mathrm{t}-1}+\alpha_{6} \text { Fert }_{\mathrm{t}-1}+\alpha_{7} \text { Pest }_{\mathrm{t}-1}+\mathrm{e}_{\mathrm{t} 3}
\end{aligned}
$$

where:

Temp $=$ temperature $\left({ }^{\circ} \mathrm{C}\right)$

Rainf $=$ rainfall $(\mathrm{mm})$

$\mathrm{Lab}=$ the amount of labour in (FCFA)

Cap= capital, i.e. the amount of depreciation of agricultural equipment used in production in (FCFA)

Fert $=$ the amount spent on fertilizer in FCFA

Pest $=$ the amount spent on pesticides in FCFA

$\Delta$ Out $=$ Change in monthly output from a change in climate variables

$\beta 1, \beta 2, \beta 3, \beta 4, \beta 5, \beta 6$ represent the coefficients to estimate the short term effects of variation in temperature, rainfall, labour, capital, fertilizer and pesticide respectively on the dependent variable (crop output) . Meanwhile $\alpha 1, \alpha 2, \alpha 3, \alpha 4, \alpha 5, \alpha 6$ are used to estimate the long run effect of changes in the independent variables on the dependent variable. 
et 1 , et 2 , et 3 are the stochastic error term for the three models

Apriori expectation is stated as follows:

$\beta 1>0, \beta 2>0, \beta 3>0, \beta 4>0, \beta 5>0, \beta 6>0$. The long run expectation is also stated as follows: $\alpha 1>0, \alpha 2>0$, $\alpha 3>0, \alpha 4>0, \alpha 5>0, \alpha 6>0$ and $\alpha 7>0$

Where $\Delta$ refers to the first difference. Therefore $\Delta$ Outt $=$ Outt - Outt-1

The model uses differences in both the dependent and the independent variables. The inclusion of the second term is the explicit formulation of the fact that we assume climate and output of the three tradables to have a longterm equilibrium relationship. More specifically, we know that any change in Outt is a sum of two effects:

The shortrun effect of the change in Climatic variablest on Outt given by $\beta$ and

The long run impact of the deviation from the equilibrium value in period $t$ adjusted at each period at the rate $\alpha$.

Table 1. Phillips - Perron unit root test statistics table for rubber

\begin{tabular}{lcccc}
\hline Variable & Test Statistics & Critical value at 1\% & Critical value at 5\% & Critical value at 10\% \\
\hline $\log ($ Output $)$ & -7.771 & -3.480 & -2.884 & -2.574 \\
$\log ($ Temperature $)$ & -5.142 & -3.480 & -2.884 & -2.574 \\
$\log ($ Rainfall $)$ & -6.886 & -3.483 & -2.885 & -2.575 \\
$\log ($ Capital $)$ & -6.188 & -3.480 & -2.884 & -2.574 \\
$\log ($ Labour cost $)$ & -8.921 & -3.480 & -2.884 & -2.574 \\
\hline
\end{tabular}

The three models were derived with the aid of the Stata 11.1 statistical package. Since the models made use of time series data, it was necessary to test for their stationarity. Consequently, the Phillips - Perron unit root test statistics was employed to test for stationarity. This was necessary to ensure the robustness of the results. The stationarity tests for the three variables, rubber, oil palm and banana are presented in Tables 1,2 and 3 respectively.

Table 2. Phillips-Perron unit root test statistics table for oil palm

\begin{tabular}{lcccc}
\hline Variable & Test Statistics & Critical value at 1\% & Critical value at 5\% & Critical value at $10 \%$ \\
\hline $\log ($ Output $)$ & -7.771 & -3.480 & -2.884 & -2.574 \\
$\log ($ Temperature $)$ & -5.142 & -3.480 & -2.884 & -2.574 \\
$\log ($ Rainfall $)$ & -6.886 & -3.483 & -2.885 & -2.575 \\
$\log ($ Capital $)$ & -6.188 & -3.480 & -2.884 & -2.574 \\
$\log ($ Labour cost $)$ & -8.921 & -3.480 & -2.884 & -2.574 \\
\hline
\end{tabular}

Table 3. Phillips - Perron unit root test statistics table for banana

\begin{tabular}{lrccc}
\hline Variable & Test Statistics & Critical value at $1 \%$ & Critical value at $5 \%$ & Critical value at $10 \%$ \\
\hline $\log ($ Output $)$ & -6.136 & -3.480 & -2.884 & -2.574 \\
$\log ($ Temperature $)$ & -5.588 & -3.480 & -2.884 & -2.574 \\
$\log ($ Rainfall $)$ & -8.003 & -3.483 & -2.886 & -2.576 \\
$\log ($ Capital $)$ & -5.628 & -3.483 & -2.885 & -2.575 \\
$\log ($ Labour cost $)$ & -7.213 & -3.483 & -2.886 & -2.576 \\
Log(fert cost $)$ & -6.708 & -3.480 & -2.884 & -2.574 \\
Log(pest cost $)$ & -5.296 & -3.480 & -2.884 & -2.574 \\
\hline
\end{tabular}

The results of the unit root (stationarity) tests for each of the variables used in the error correction model 
equations for the different crops confirm that all the variables were stationary after the first differencing. In addition, the Durbin Watson test for the presence of serial correlation and the semi-robust standard error was used to take care of potential problems of heteroskedasticity.

\section{Results}

\subsection{Climatic Variations in the Rubber Estates}

As earlier mentioned, the two climatic elements considered are temperature and rainfall. The temperature trend for the rubber plantations is not relatively constant. Significant variations could be observed between the period 1995-2010 (Figure 2).

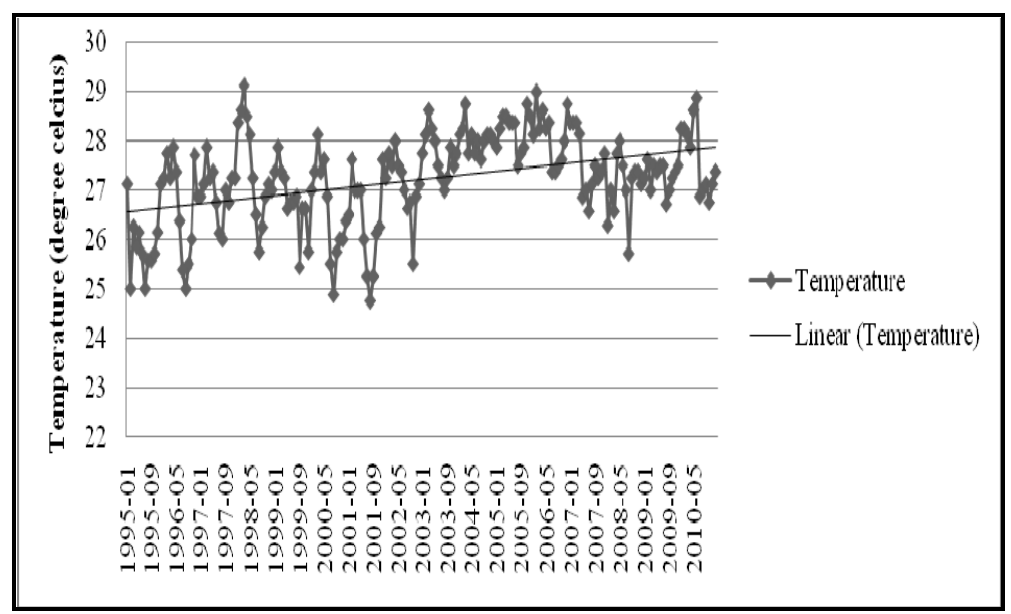

Figure 2. Average temperature trend for the rubber estates

Source: Computed from CDC Records, 2011.

Similarly, there are observed variations in rainfall for the 16 year period in the banana plantations (Figure 3). The general trend of rainfall shows a decline until 2009 when it registered a very sharp rise with the number of rainy days actually rising above the upper limit of 150 days. This indicates the occurrence of rainfall variability and unreliability in the $\mathrm{CDC}$ rubber estates.

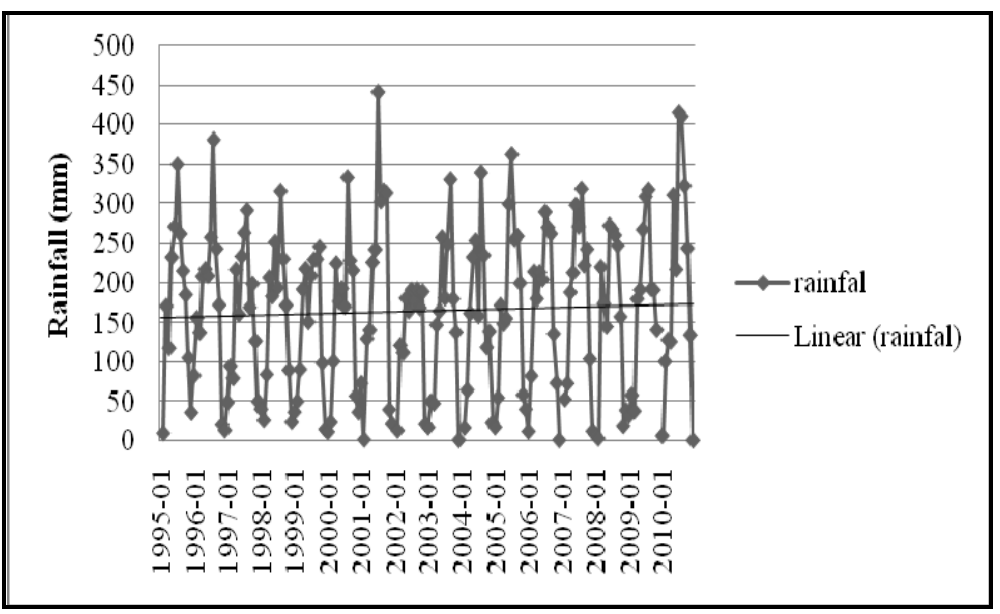

Figure 3. Average temperature trend for the rubber estates

Source: Computed from CDC Records, 2011. 


\subsection{Climatic Variations in the Oil Palm Estates}

Figure 4 shows that average temperature has been witnessing less significant fluctuations around the West Coast area which harbours most of the oil palm estates of the CDC. However, it demonstrates a high degree of monthly variability.

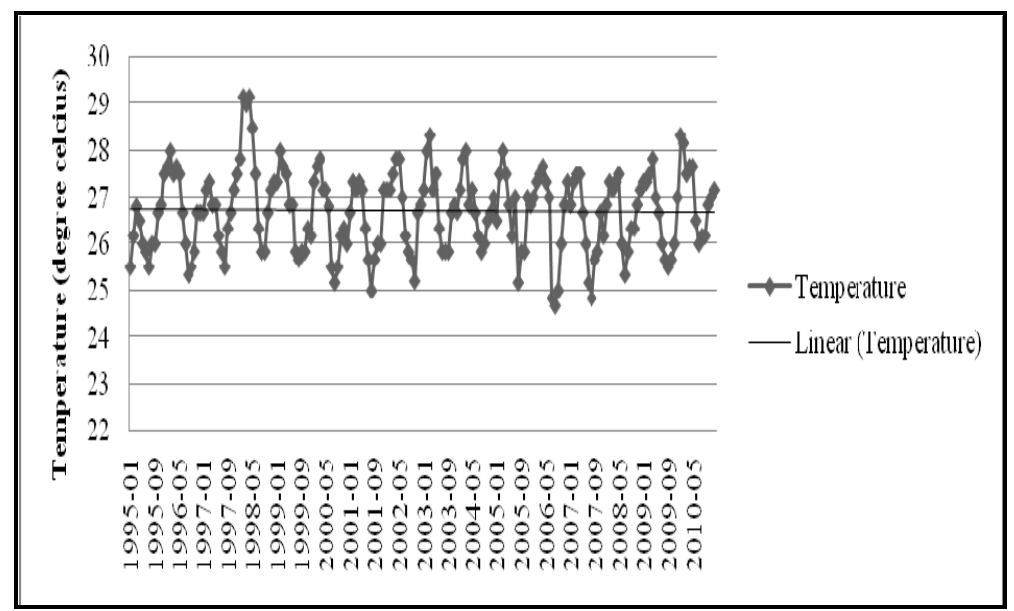

Figure 4. Average Temperature Trend for the oil palm estates

Source: Computed from CDC Records, 2011.

There is an observed variation in rainfall for the oil palm estates for the years under study (Figure 5). Also, there is evidence of an upward rainfall trend between 1995 and 2010.

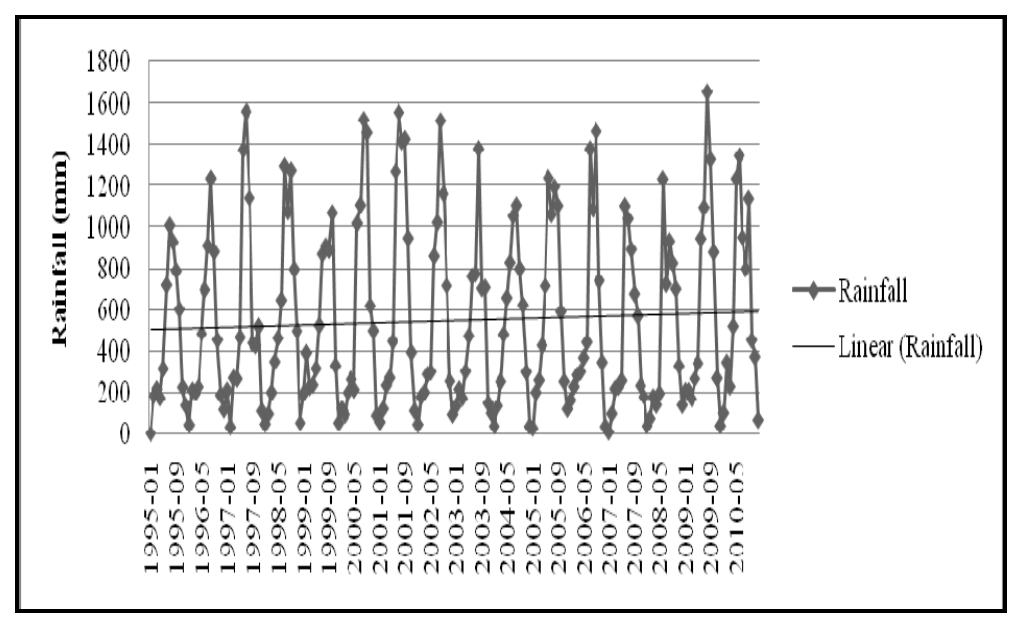

Figure 5. Average Temperature Trend for the oil palm estates

Source: Computed from CDC Records, 2011.

\subsection{Climatic Variations in the Banana Plantation}

Figure 5 shows that temperature trend for the banana estates is not relatively constant. A significant increase in temperature is observed for the banana plantations with some less significant variations. Generally, the graph shows that temperature is positively skewed. Despite the less significant variations, the effects are significant on the banana crop given its relatively high degree of sensitivity to climatic alterations. 


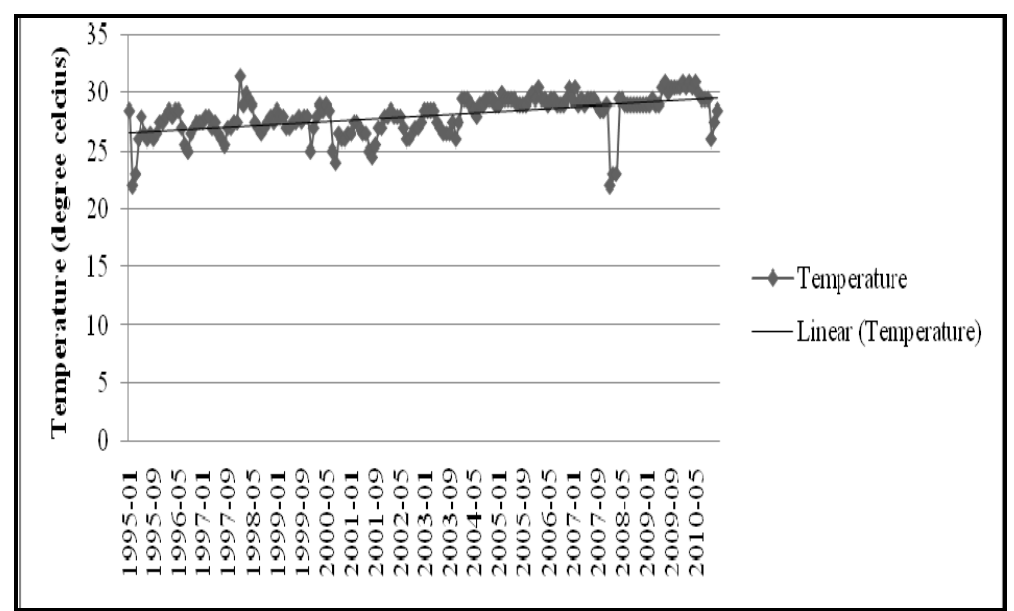

Figure 5. Average temperature trend for the banana plantations

Source: Computed from CDC Records, 2011.

In the same vein, but from a more significant standpoint, the banana plantations are exposed to variations in rainfall (Figure 6).

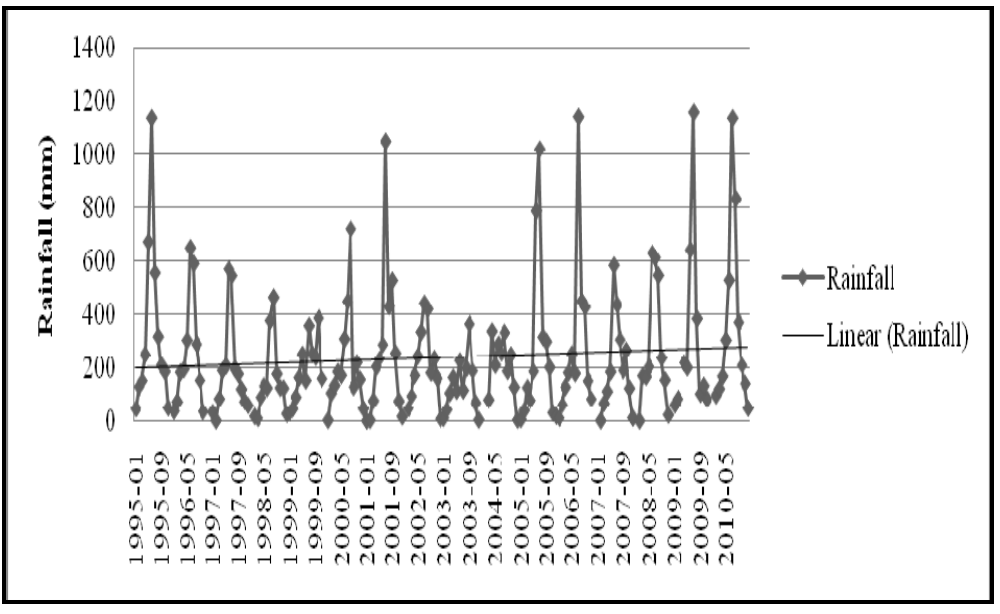

Figure 6. Average temperature trend for the banana project

Source: Computed from CDC Records, 2011.

\subsection{Effects of Climatic Variations on the CDC Crops}

For experimental and quasi-experimental designs, there must be a description of the flow of participants (human, animal, or units such as classrooms or hospital wards) through the study. Present the total number of units recruited into the study and the number of participants assigned to each group. Provide the number of participants who did not complete the experiment or crossed over to other conditions and explain why. Note the number of participants used in the primary analyses. (This number might differ from the number who completed the study because participants might not show up for or complete the final measurement.)

\subsection{Effects of Climatic Variations on the CDC Crops}

Table 4 shows the regression results of the short and long term effect of variations in climate on the output of rubber, oil palm and banana. For all the tradables, output for the different climate and socio economic parameters were regressed to estimate the quantitative effect of each of these explanatory variables on the outputs of rubber, oil palm and the banana. The results are analysed separately to permit us to capture the different rates at which variations in climatic normals affect agricultural output of the three tradables. 
Table 4. Regression results for the three tradables

Dependent variable: $\log$ (Crop Output)

Method: Error Correction Model

Independent variables: $\log$ (Temp.) $\log$ (Rain.) $\log$ (cap.) $\log$ (lab.) $\log$ (Fert.) $\log$ (Pest)

\begin{tabular}{|c|c|c|c|}
\hline Variable & $\begin{array}{l}\text { Coefficient } \\
\text { (t statistics) } \\
\text { Rubber }\end{array}$ & $\begin{array}{l}\text { Coefficient } \\
\text { (t statistics) } \\
\text { Oil palm }\end{array}$ & $\begin{array}{l}\text { Coefficient } \\
\text { (t statistics) } \\
\text { Banana }\end{array}$ \\
\hline$\Delta . \log ($ Temp. $) \mathrm{t}$ & $\begin{array}{l}-2.7619 * * \\
(-2.56)\end{array}$ & $\begin{array}{l}5.5042 * * * \\
(5.61)\end{array}$ & $\begin{array}{l}-.3614 * * * \\
(-0.93)\end{array}$ \\
\hline$\Delta . \log$ (Rain.)t & $\begin{array}{l}-0.0723^{* * *} \\
(-2.86)\end{array}$ & $\begin{array}{l}-.1179 * * * \\
(-4.34)\end{array}$ & $\begin{array}{l}-.0506 * * * \\
(-3.36)\end{array}$ \\
\hline$\Delta . \log ($ Capital $) \mathrm{t}$ & $\begin{array}{l}0.0994 \\
(1.02)\end{array}$ & $\begin{array}{l}-.0125 \\
(-0.28)\end{array}$ & $\begin{array}{l}.4574 * \\
(1.86)\end{array}$ \\
\hline$\Delta \cdot \log ($ Lab.cost $) t$ & $\begin{array}{l}0.0552 \\
(0.83)\end{array}$ & $\begin{array}{l}.0883 * \\
(1.69)\end{array}$ & $\begin{array}{l}.2209^{* *} \\
(2.25)\end{array}$ \\
\hline$\Delta \cdot \log ($ Fert.cost $) t$ & & & $\begin{array}{l}.0981 * \\
(1.89)\end{array}$ \\
\hline$\Delta \cdot \log ($ Pest.cost $) t$ & & & $\begin{array}{l}.1137^{* *} \\
(2.16)\end{array}$ \\
\hline $\log ($ Temp.)t-1 & $\begin{array}{l}-2.3242^{* * *} \\
(-2.82)\end{array}$ & $\begin{array}{l}2.3320 * * \\
(2.55)\end{array}$ & $\begin{array}{l}-.2684 * * \\
(0.94)\end{array}$ \\
\hline $\log$ (Rain.)t-1 & $\begin{array}{l}0.0140 \\
(0.52)\end{array}$ & $\begin{array}{l}-.2486^{* * *} \\
(-9.99)\end{array}$ & $\begin{array}{l}-.0517 * * * \\
(-3.36)\end{array}$ \\
\hline $\log ($ Capital $) t-1$ & $\begin{array}{l}0.0856 \\
(0.79)\end{array}$ & $\begin{array}{l}-.0332 \\
(-0.62)\end{array}$ & $\begin{array}{l}-.0200 \\
(-0.50\end{array}$ \\
\hline $\log ($ Lab.cost $) t-1$ & $\begin{array}{l}0.0293 \\
(0.30)\end{array}$ & $\begin{array}{l}.1061 * \\
(1.75)\end{array}$ & $\begin{array}{l}.1388 \\
(1.58)\end{array}$ \\
\hline $\log ($ Fert.cost $) t-1$ & & & $\begin{array}{l}.0131^{*} \\
(0.21)\end{array}$ \\
\hline $\log ($ Pest.cost $) \mathrm{t}-1$ & & & $\begin{array}{l}.1325^{* * *} \\
(3.60)\end{array}$ \\
\hline $\mathrm{C}$ & $\begin{array}{l}10.6409 * * * \\
(3.39)\end{array}$ & $\begin{array}{l}-5.1599 * \\
(-1.75)\end{array}$ & $\begin{array}{l}.9720 * \\
(0.67)\end{array}$ \\
\hline R-squared & 0.3726 & 0.6848 & 0.4220 \\
\hline Adjusted R2 & 0.3398 & 0.6691 & 0.3722 \\
\hline No. of Obs. & 192 & 191 & .165 \\
\hline F - Statistics & 11.35 & 43.69 & 8.48 \\
\hline Prob (F-stats) & 0.0000 & 0.0000 & 0.0000 \\
\hline Durbin Watson statistics & 1.8987 & 1.6694 & 1.8661 \\
\hline
\end{tabular}

T-statistics in parenthesis. Note: * Significant at $10 \%$ level.

** Significant at $5 \%$ level. *** Significant at $1 \%$ level. 


\section{Discussion}

\subsection{Rubber}

The results revealed that an increase in temperature with rainfall held constant exerts a negative effect on rubber output. This result is significant at 5\%. It implies that any increase in temperature will likely result in decreasing rubber output. This may be due to the fact that high temperatures increase the rate of the spread of diseases as well as plant dehydration (Table 4). The estimated marginal effect shows that when current monthly temperature increases by $1^{\circ} \mathrm{C}$, current rubber output will reduce by 2.76 tons in absolute terms. The long run results show that increase in temperature in the previous month by $1^{\circ} \mathrm{C}$ leads to a fall in the current month's output by 2.32 tons. This result is significant at $1 \%$. Thus high temperatures exhibit a negative influence on rubber output both in the short and long run periods.

A change in rainfall has a negative effect on rubber output and this is significant at $1 \%$. It implies that an increase in rainfall will reduce rubber output; in absolute terms, an increase in rainfall by $1 \mathrm{~mm}$ will result to a drop in output by 0.07 tons (Table 4). This may be due to the fact that more rainfall could lead to a reduction in the number of tapping days since tapping in the CDC is suspended on rainy days- especially the early morning rains. Also, rainfall washes out the latex from the cups after tapping. The long run results show that the coefficient for rainfall is positive. This implies that there is a direct relationship between the previous month's rainfall and current output of rubber. This could be noticed through increased soil moisture that provides a medium for nutrient dissolution and the decay of biomass that boost the production of latex. For instance, a percentage change in previous rainfall will cause long run output of rubber to increase by $0.01 \%$. This result is consistent with the a priori expectation. Considering the calculated t-value of $(0.52)$ and the table $t$ value of 1.833 , the result is statistically not significant at $10 \%$ two tail test.

Monthly depreciation cost is used to capture monthly capital investment. The results shows that there is a direct positive short term relationship between capital investment and rubber output. This investment may include spending on replanting of the old plantations, spending on machineries like trucks, bulldozers, forklift trucks and industrial tractors. A $1 \%$ change in capital investment will result to $0.09 \%$ change in output. However, with a calculated $t$-value of (1.02) and the table $t$-value of 1.833 , the result is statistically not significant at $10 \%$ two tail test. As concerns the long run effects of capital investment, the coefficient is also positive. This implies that previous month capital investment has a positive effect on current output. For example, a percentage change in previous capital investment will result to a $0.08 \%$ increase in current output, everything being equal. The calculated t-value in absolute terms is 0.79 , while the table t-value is 1.833 at $10 \%$ two tail test. The table t-value is greater than the calculated t-value in the short and long run situation indicating that despite the positive relationship between capital investment and rubber output, the result is not significant.

The positive coefficient for labour cost also indicates a direct relationship between labour expenditure and rubber output. It shows that there is a direct positive short and long term relationship between labour expenditure and rubber output. This expenditure may include the spending on training, expertise, bonuses, fringe benefits, spending on additional workers in the farms as well as other spending to motivate workers. A percentage change in labour expenditure will lead to a $0.05 \%$ increase in output in the short run, and a $0.02 \%$ increase in output in the long run. However, with a calculated t-value of 0.83 and 0.30 respectively, and the table t-value of 1.83 , the result is statistically not significant at $10 \%$ two tail test.

The R-squared of the output equation is 0.37 . This shows that $37 \%$ of the variation in rubber output is explained by the combined effect of all the independent variables considered in the equation. The calculated F-statistics is 11.35 with a table value of 10.6 at $1 \%$ level of significance. Since the calculated F-statistics is greater than the table F-statistics, it is an indication that the overall results are significant even at $1 \%$ two tail test and therefore, more than $99 \%$ reliable. This is further confirmed by the probability of the F-statistics which is given as 0.0000 showing a zero probability of committing a type II error.

\subsection{Oil Palm}

Temperature exerts a positive effect on oil palm output. This result is significant at $1 \%$ and implies that a change in temperature will result to a change in oil palm output. The estimated marginal effect shows that when current monthly temperature increases by $1 \%$, current output will increase by $5.5 \%$. The long run results shows that an increase in temperature in the previous month by $1 \%$ leads to an increase in the current month's output by $2.3 \%$ and this is statistically significant at $1 \%$. Rainfall is revealed to be significant at $1 \%$ and it has a negative effect on oil palm output. It implies that an increase in rainfall reduces oil palm output. From Table 4, an increase in rainfall by $1 \mathrm{~mm}$ will result to a drop in output by 0.12 tons in absolute terms. This may be due to the fact that excess rainfall might exceed the rainfall threshold for the plant and negatively affect its growth. It could also 
affect its flowering especially when accompanied by wind. The long run results shows that an increase rainfall for the previous month by $1 \mathrm{~mm}$ will reduce current oil palm output by 0.25 tons in the current month and this is statistically significant at $1 \%$.

The results in Table 4 show that there is an inverse relationship between capital investment and oil palm output. An increase in capital investment by $1 \%$ could lead to $0.01 \%$ decrease in output. Meanwhile a positive change in the previous month capital investment by $1 \%$ could cause output to decrease by $.03 \%$ in absolute terms in the following month. With a p-value of 0.535 , the results are statistically insignificant at $10 \%$.

Labour cost indicates the existence of a direct relationship between labour investment and output. An increase in labour expenditure causes oil palm's output to increase. The investment in labour includes spending on training, spending on expertise services, fringe benefits and spending to motivate workers. More specifically, a unit increase in labour spending could lead to .09 tons increase in output at $10 \%$ level of significance. As concerns the long term effects, the results indicate that with an increase of $1 \%$ in labour spending in the previous month, current month output will increase by $.12 \%$ in absolute terms. With a p-value of 0.082 , this result is statistically significant at $10 \%$. The $\mathrm{R}$ - squared of the output equation is 0.6848 . This shows that $68 \%$ of the variations in oil palm output is explained by the combined effect of all the independent variables considered in the equation. The calculated F-statistics is 43.69 with a table value of 4.6, it is statistically significant at $1 \%$. Since the calculated F-statistics is greater than the table F-statistics, this shows that the overall results are statistically significant even at $1 \%$ two tail test and therefore, more than $99 \%$ reliable. This is further confirmed by the probability of Fstatistics which is given as 0.0000 showing a zero probability of committing a type II error.

\subsection{Banana}

Temperature variations show a negative effect on banana output. This may be due to the fact that high temperature dehydrates the banana plant, thus affecting its growth. Although heat is needed for the growth of the banana plant, higher than normal temperatures stress the fragile plant leading to lower quality of banana and a reduction in output. The estimated marginal effect shows that when current monthly temperature increases by $1^{\circ} \mathrm{C}$, current banana output will reduce by 0.36 tons (Table 4). The long run results show that an increase in temperature in the previous month by $1{ }^{\circ} \mathrm{C}$ leads to a fall in the current month's output by 0.27 tons, and this is statistically significant at $10 \%$.

Rainfall is significant at $1 \%$ and has a negative effect on banana output. It implies that any increase in rainfall will reduce banana output. From Table 4, an increase in rainfall by $1 \mathrm{~mm}$ will result to a drop in output by .12 tons. This may be due to the fact that current rainfall pattern is already above the required for optimum production. As such, more rainfall could lead to slower rates of fruit development. The long run results show that an increase in the previous month rainfall by $1 \mathrm{~mm}$ will lead to a decrease in banana output by 0.05 tons in absolute terms for the current month. This result is statistically significant at $1 \%$.

Capital investment (Table 4) shows that there is a direct positive relationship between capital investment and banana output. Increase in capital investment by $1 \%$ could lead to a $0.46 \%$ increase in output. The p-statistics value is 0.065 indicating that the result is significant at $10 \%$. Meanwhile a change in the previous month capital investment by $1 \%$ could cause output to decrease by $0.02 \%$ in the following month. However, with a p-value of 0.617 , the long run result is statistically insignificant. The positive coefficient for labour cost indicates a direct relationship between labour investment and output. An increase in labour cost causes banana output to increase. As such labour in this model has a positive effect on the output of banana. The investment in labour includes the spending on training, spending on expertise services, fringe benefits and spending to motivate workers. More specifically, a $1 \%$ increase in labour spending could lead to $0.22 \%$ increase in output and it is significant at $5 \%$. As concerns the long term effects, the results indicate that a $1 \%$ change in labour spending in the previous month will cause current output to increase by $0.14 \%$. With $\mathrm{P}$ value of 0.117 the long run result is statistically insignificant.

Fertilizer cost in this model has a positive influence on banana output. For example, a $1 \%$ change in cost of fertilizers will result to a $0.098 \%$ increase in the output of banana. From the table, the calculated t-value in absolute terms is 1.89 , while the Table T-value is 3.250 at $10 \%$ level of significance. This means that fertilizer cost is statistically significant in explaining the variation in banana output. The long run coefficient for fertilizer is also positive. This shows that a $1 \%$ increase in fertilizer cost in the previous month causes current output to increase by $0.01 \%$. However, with a p-value of 0.037 , the result is statistically significant at $10 \%$ two tail test.

The results also show that the coefficient of pesticide cost is positive both in the short and long run. This implies that pesticide cost has a positive influence on banana output (Table 4). For example, a $1 \%$ change in the cost of pesticides will result to a $0.11 \%$ increase in the output of banana in the short run and it is statistically significant 
at $5 \%$.In the long run it will lead to a $0.13 \%$ increase in banana output. This result is statistically significant at $1 \%$ two tail test.

The R-squared of the output equation for banana is 0.4220 . This shows that $42 \%$ of the variations in banana output is explained by the combined effect of all the independent variables considered in the equation. Since the calculated F-statistics is greater than the table F-statistics, this shows that the overall results are significant even at $1 \%$ two tail test. This is further confirmed by the probability of F-statistics which is given as 0.0000 showing a zero probability of committing a type II error.

\section{Recommendations}

Faced with the observed effects of climatic variations on the CDC, the following holistic and crop-specific adaptation options should be considered:

The CDC should consider the need to put in place a climate adaptation plan which should involve actions that can enable her crops to cope with this situation. From a holistic perspective, this may include the following:

Capacity building for personnel to identify the climate-related problems and possible mitigation and adaptation measures. Since the personnel capacity is never static, and requires continuous renewal, it is necessary for capacity building to be adopted so that the skills of the personnel of the Research Department of the CDC should be improved upon in the realm of managing climatic variations.

There is a need to strengthen the climate monitoring networks to be able to indicate the detail current weather pattern and inform the CDC management on what to do. That is, Early Warning Systems (EWS) should be introduced. This should be complemented by an Epidemiological Surveillance Network which signals the outbreak of emerging climate-related diseases affecting CDC crops. This is important because the observed variations also create breeding grounds for emerging diseases.

Since increasing temperatures and drier conditions affect most of the crops, especially banana, it is recommended that the CDC Research Department in collaboration with the Institute for Agricultural Research for Development (IRAD) Ekona should look at the possibility of introducing more drought and disease-resistant crop species for the three crops. More studies could be done on the role of new technologies, particularly tillage systems, genetic innovations and irrigation technologies and its impact on corporate agricultural performance in the phase of the changing weather

Perhaps, with the ongoing development of the National Climate Change Monitoring Centre, it is necessary to indicate that outreach stations should be created in the CDC area given its significant contribution to national development.

To reduce the effect of evapotranspiration for the rubber crop, tapping in the dry season should be adjusted to begin at $4.30 \mathrm{am}$ and not $6.30 \mathrm{am}$ with the use of superior quality headlights. There is high turgor pressure and low transpiration in the early hours of the morning which favours latex flow and substantially reduces the percentage of field coagulum. In addition, during such rainy periods, the CDC should consider the use of rain guards (Cutter type-umbrella method) to prevent the high rates of wash off of latex from the rubber tree and regain of lost tapping days due to rainfall interference.

For the banana sector, there is a need to supplement the present electric irrigation network in the dry season with standby generators to ensure the continuous supply of water to the plant even when there is electricity failure. The drainage network should be improved upon to avoid water logging in the face of increasing rainfall in the rainy season.

There is a need to consider expanding the oil palm plantations which, according to the results of this study, show a positive relationship with increase in temperature.

\section{Conclusion}

From the above observations, the following conclusions can be drawn; there are observed variations in temperature and rainfall for the CDC plantations sites understudy. Variations in temperature and rainfall affect the $\mathrm{CDC}$ tradables and their effects are felt in different magnitudes. The present adaptation strategies put forth by the CDC are inadequate and this could be buttressed by the persistence of the effects of such variations on the CDC crops. These observations all align with the proven studies that the agricultural systems are greatly affected by the effect of short and long term variations in climate. It is projected that crop yield in Africa may fall by $10-20 \%$ by 2050 or even up to $50 \%$ due to climate change (Jones \& Thornton, 2003), particularly because African agriculture is predominantly rain-fed and hence fundamentally dependent on the vagaries of weather. As the people of Africa strive to overcome poverty through agricultural development (Zoellick, 2009), many 
researchers have incorporated adaptation in their climate change effect models in an attempt to improve the theoretical and empirical approaches to explain the features of problems linked to climatic variations and measurements of the effect of such variations on agriculture. It can then be concluded that the future of adaptation measures geared towards the improvement of the output of these CDC tradables lies in a balance; the effective adoption of the suggested recommendations could guarantee better adaptation options for improved crop yields; however, if such measures are not adhered to, it is evident that more significant fluctuations in output should be expected; this does not augur well for the CDC given her crucial role in the regional development process of Cameroon (Fossung, 2001).

\section{References}

Cameroon Development Corporation. (1995-2010). Annual Reports.

Cameroon Development Corporation. (2000-2010). Approved Consolidated Budget Booklets.

CDC. (1995-2010). Group Rubber Monthly Activity Reports.

CDC. (1995-2010). Group Oil Palms Monthly Activity Reports.

CDC. (1995-2010). Group Banana Monthly Activity Reports.

Fossung, E. Y. W. (2001). The Role of Plantation Agriculture in Regional Development: The Case of the Cameroon Development Corporation. In C. M. Lambi \& B. E. Eze (Eds.), Readings In Geography, Unique Printers Bamenda.

Jones, P. G., \& Thornton, P. K. (2003). The Potential Impacts of Climate Change In Tropical Agriculture: The Case of Maize in Africa and Latin America in 2055. Global Environmental Change, 13, 51-59. http://dx.doi.org/10.1016/S0959-3780(02)00090-0

Kimengsi, J. N. (2009). Pamol Industrial Growth and Land Use Conflicts in Ekondo-Titi Sub-Division, South West Region of Cameroon. Proceedings of the 2nd Post Graduate Seminar Organised on January 28th 2009 on Conflict Resolution, Prevention and Management by the Faculty of Social and Management Sciences, University of Buea, Cameroon.

Kimengsi, J. N. (2008). The Contribution of Pamol Plantation and Its Associated Environmental Impacts to the Development of Ekondo-Titi Sub-Division, South West Province of Cameroon. Unpublished M.Sc. Thesis, Department of Geography, University of Buea.

Lordemann, J. A., \& Salas, T. J. A. (2009). The Climate Change Effects on the Agricultural Sector of Bolivia. Instituto de Investigaciones Socio-Económicas (IISEC), Universidad Católica Boliviana. Retrieved from http://ideas.repec.org/f/pal424.html

Molua, E. L., \& Lambi C. M. (2006). The Economic Impact of Climate Change on Agriculture in Cameroon. CEEPA paper No 17, Centre for Environmental Economics and Policy in Africa, University of Pretoria.

Okunmedewa, F. (2003). Risk Vulnerability in Agriculture; Concept and Context. A Paper Presented at the Development of Agricultural Economics, University of Ibadan, Ibadan, Nigeria.

Oyekale A. S., Bolaji, M. B., \& Olowa, O. W. (2009). The Effects of Climate Change on Cocoa Production and Vulnerability Assessment in Nigeria. Agricultural Journal, 4(2), 77-85.

Slingo, J. M., Challinor, A. J., Hiskins, B. J., \& Wheeler, T. R. (2005). Introduction: Food Crops in a Changing Climate. Philosophical Transactions of the Royal Society, Series B, 360, 1983-1989. http://dx.doi.org/10.1098/rstb.2005.1755

Thomas, D. S. G., \& Twyman, C. (2005). Equity and Justice in Climate Change Adaptation Amongst Natural-Resource-Dependent Societies. Global Environmental Change, 15, 115-124. http://dx.doi.org/10.1016/j.gloenvcha.2004.10.001

Thornton, P. K., Jones, P. G., Owiyo, T., Kruska, R. L., Herrero, M., Kristjanson, P., ... Kulkar, U. (2006). Mapping Climate Vulnerability and Poverty in Africa. Report to the Department for International Development, ILRI, PO Box 30709, Nairobi 00100, Kenya. p. 171.

Zoellick. (2008). A Climate Smart Future. The Nations Newspapers. (p. 18). Lagos, Nigeria: Vintage Press Limited. 